\title{
Aa. Vv., «Cahiers Tristan l'Hermite», XXVI, XXVII, XXVIII
}

Daniela Dalla Valle

\section{(2) OpenEdition}

12 Journals

\section{Edizione digitale}

URL: http://journals.openedition.org/studifrancesi/8901

DOI: 10.4000/studifrancesi.8901

ISSN: 2421-5856

\section{Editore}

Rosenberg \& Sellier

\section{Edizione cartacea}

Data di pubblicazione: 1 octobre 2008

Paginazione: 450

ISSN: 0039-2944

\section{Notizia bibliografica digitale}

Daniela Dalla Valle, «Aa. VV., «Cahiers Tristan I'Hermite», XXVI, XXVII, XXVIII», Studi Francesi [Online],

155 (LII | II) | 2008, online dal 30 novembre 2015, consultato il 12 janvier 2021. URL: http://

journals.openedition.org/studifrancesi/8901; DOI: https://doi.org/10.4000/studifrancesi.8901

Questo documento è stato generato automaticamente il 12 janvier 2021.

\section{(c) (i) $\odot$}

Studi Francesi è distribuita con Licenza Creative Commons Attribuzione - Non commerciale - Non opere derivate 4.0 Internazionale. 


\title{
Aa. Vv., «Cahiers Tristan l'Hermite», XXVI, XXVII, XXVIII
}

\author{
Daniela Dalla Valle
}

\section{NOTIZIA}

«Cahiers Tristan l'Hermite», XXVI (2004), XXVII (2005), XXVIII (2006).

Riprendiamo con qualche ritardo la presentazione della rivista annuale dedicata a Tristan l'Hermite, descrivendo brevemente i numeri ormai un po' lontani nel tempo, per occuparci d'ora in poi regolarmente dei numeri recenti.

«Cahiers Tristan l'Hermite», XXVI, 2004, pp. 111.

4 Il fascicolo è intitolato Nouvelles perspectives tristaniennes. A. LABENHEIM (Une esthétique du flou, entre dissimulation et travestissement) analizza la tematica suggerita dal suo titolo in una lunga serie di testi poetici (Amours, Vers héroïques, Lyre), di testi teatrali (Mariane, Panthée, Folie du Sage, Mort de Sénèque, Mort de Chrispe, Parasite) e di testi in prosa (Lettres meslées). G. PEUREUX (Un douloureux sillon diversement creusé. Notes sur Tristan et les misères humaines) si sofferma invece sulle opere religiose di Tristan, riprendendo e puntualizzando analisi precedenti di Amédée Carriat. L. PHILIPPS (Sens et pratique de l'achèvement dans les "Vers héroïques") si sofferma su una sola raccolta poetica, mentre S. TONOLo (L'Epître chez Tristan) sceglie come oggetto di lavoro le epitres poétiques. Infine F. DUVAL e A.M. SPICA ("Le Cabinet de Louis XI" ou l'histoire d'une imposture) analizzano il breve testo storico del fratello di Tristan, Jean-Baptiste l'Hermite.

5 Gli articoli del fascicolo sono preceduti dal ricordo affettuoso di Amédée Carriat, autentico creatore del gusto letterario per Tristan e responsabile della pubblicazione dei «Cahiers».

7 «Cahiers Tristan l'Hermite», XXVII, 2005, pp. 78. 
8 Il fascicolo riunisce le comunicazioni della Journée d'étude del 15 gennaio 2005 sul Page disgracié. S. BERREGARD ( $L a$ folie du page ou le sage disgracié) mette a confronto due testi tristaniani, il romanzo e la Folie du sage. F. ORWAT (Galanterie et tentation mondaine dans le "Page disgracié") si sofferma a sottolineare l'influenza di Castiglione sul romanzo di Tristan.

9 L. PHILIPPS (Tristan chez Cyrano) ricerca la presenza di Tristan nell'Autre Monde. F. D’ANGelo (Aspects de la mise en intrigue dans le "Page disgracié") analizza invece la configurazione narrativa coerente del Page. P. RIARD (Le page et son initiation: quelle alchimie pour devenir poète?) si sofferma sulla dimensione d'iniziazione alla poesia del romanzo. Infine A. GENÉTIOT (Les poèmes du "Page disgracié") presenta e commenta i versi inseriti nel romanzo.

11 «Cahiers Tristan l'Hermite», XXVIII, 2006, pp. 111.

12 Il fascicolo è dedicato a Jacques Morel, recentemente scomparso, illustre cultore della poesia e del teatro tristaniano. Comprende una serie di articoli i cui titoli suggeriscono esplicitamente l'argomento: S. BERREGARD (Tristan et la pastorale: des "Plaintes d'Acante" à l"'Amarillis"), L. thOMmeret (L'autonomie du lyrisme dans "Panthée"), A. LABENHeIM ("Un mixte composé de lumière et de fange': une stylisation du contraste chez Tristan l'Hermite), L. PHILIPPS (Le poète et le Prince dans les "Vers héroïques": agonie d'une relation mythique). Il fascicolo è concluso dalla presentazione di due odi di Tristan e di Adam Billaut dedicate a Gaston d'Orléans, presentazione di L. PHILIPPS. 